\title{
Three Dogs Under 2 Years of Age with Heartworm Caval Syndrome
}

\author{
Yuichi HIDAKA $^{1)}$, Mitsuyoshi HAGIO ${ }^{1) *}$, Takayuki MURAKAMI ${ }^{2)}$, Syozo OKANO ${ }^{3)}$, Koichi NATSUHORI ${ }^{4)}$ and \\ Norio NARITA ${ }^{5)}$
}

${ }^{1)}$ Departments of Veterinary Surgery and ${ }^{2)}$ Veterinary Anatomy, Faculty of Agriculture, Miyazaki University, 1-1 Gakuen Kibana dai nishi, Miyazaki 889-2192, 3) Department of Small Animal Clinics, Kitasato University, 23-35-1 Higashi, Towada City, Aomori 034-8628, 4) Fuji Animal Hospital, 2-3 Nejirobabagashira, Hachinohe City, Aomori 039-1166 and ${ }^{5}$ Narita Animal Hospital, 2-4-35 Tsukuda, Aomori City, Aomori 030-0962, Japan

(Received 20 January 2003/Accepted 4 July 2003)

ABSTRACT. Heartworm caval syndrome (CS) occurred in three dogs under 2 years of age. A 23-month-old dog was recovered by surgical and medical treatments, but the other 2 dogs (15 and 21 months old) died. Necropsy demonstrated 12 heartworms in the 15-month-old dog and 8 worms in the 21-month-old dog. Histopathologically, pulmonary arterial embolism caused by dead worms and thrombi were observed in these cases. The findings suggested that CS could develop regardless of canine age and worm burden if pulmonary arterial embolism related to worm death or thrombus formation were induced

KEY WORDS: dog under 2 years old, heartworm caval syndrome, pulmonary arterial embolism.

Caval syndrome (CS) is well known as a type of heartworm disease, and shows sudden onset of depression, anorexia, dyspnea, pale mucous membrane, hemoglobinuria, systolic murmur in the right-side of the heart and jugular vein distention $[1-6,9,12]$. Canine CS is common in highly endemic regions of heartworms and seen in average 5-yearold, male dogs in spring to early summer [1-3, 9, 12]. In general, it is recognized that most dogs with CS have a heavy worm burden in the right ventricle, right atrium and cranial and caudal venae cavae $[1-4,9,10,12]$. The authors encountered three dogs less than 2 years of age with CS and with fewer worms than in conventional canine CS. In this article, we describe the ante- and post-mortem findings in these 3 dogs.

Case No. 1: A 15-month-old, male Shiba Inu was admitted to a local veterinarian with a history of depression and anorexia. A test for heartworm antigen (VetRED CHW ${ }^{\circledR}$, Kyoritsu Seiyaku Co., Tokyo, Japan) was negative. Thoracic radiography demonstrated severe right-sided heart enlargement and dilated and tortuous pulmonary arteries. Echocardiography visualized a moderate number of heartworm echoes in the right atrium. These findings indicated that the dog had CS and immediate heartworm removal with a straight or rigid alligator forceps via jugular venotomy was performed, but no worms could be taken. The dog died the next morning. At necropsy, 3 adult male and 6 adult female worms were recovered from the right atrium and right ventricle, and 3 adult females from the pulmonary arteries (a total of 12 worms). Microscopically, remarkable changes were pulmonary arterial embolism caused by dead worms and thrombi. Dead worm-related embolisms were observed in the pulmonary arteries distributed in the right cranial and right caudal lung lobes and these dead worms had almost

\footnotetext{
* Correspondence to: Hagio, M., Department of Veterinary Surgery, Miyazaki University, 1-1 Gakuen Kibana dai nishi, Miyazaki 889-2192, Japan.
}

intact internal structures (Fig. 1). Thrombi were extensively seen from large elastic type arteries to capillaries. A few heartworms that were probably alive when the dog died were also detected. Villous proliferative intimal lesions were limited to part of the pulmonary arteries in the right and left caudal lung lobes.

Case No. 2: A 21-month-old, male Siberian Husky, weighing $22.3 \mathrm{~kg}$, had a 5-day history of depression and anorexia. The dog had received vaccinations and anti-helminthics against Toxocara canis at 3- and 4-months old. On routine blood work, the WBC count $\left(25.2 \times 10^{2} / \mu l\right)$, plasma alkaline phosphatase activity $(279 \mathrm{IU} / l)$ and blood urea nitrogen concentration $(59.9 \mathrm{mg} / \mathrm{d} l)$ were increased. The $\mathrm{RBC}$ count $\left(510 \times 10^{4} / \mu l\right)$ and packed cell volume $(40 \%)$ were in the normal ranges. Thoracic radiographs revealed

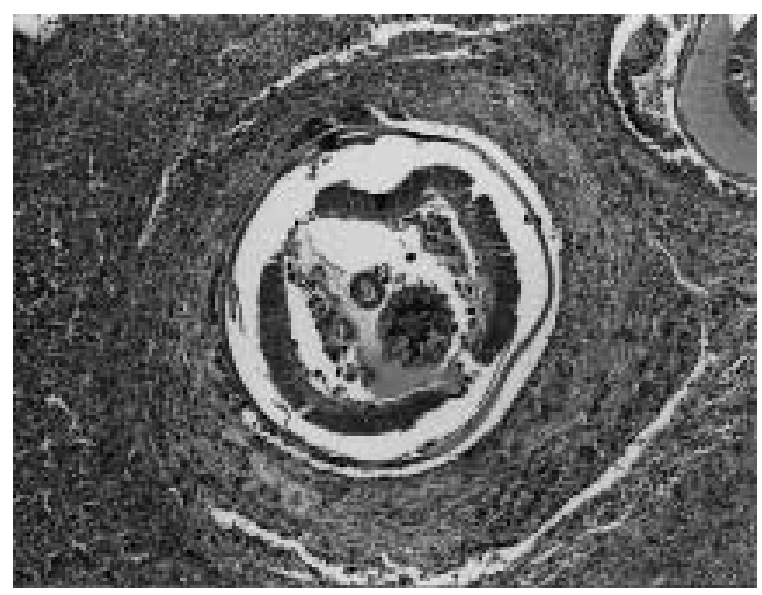

Fig. 1. Microphotograph in Case No. 1, showing pulmonary arterial embolism caused by dead worms with relatively fresh internal structures in the right cranial lung lobe. The arterial wall showed granulomatous reaction. Hematoxylin and eosin stain $(\times 48)$. 

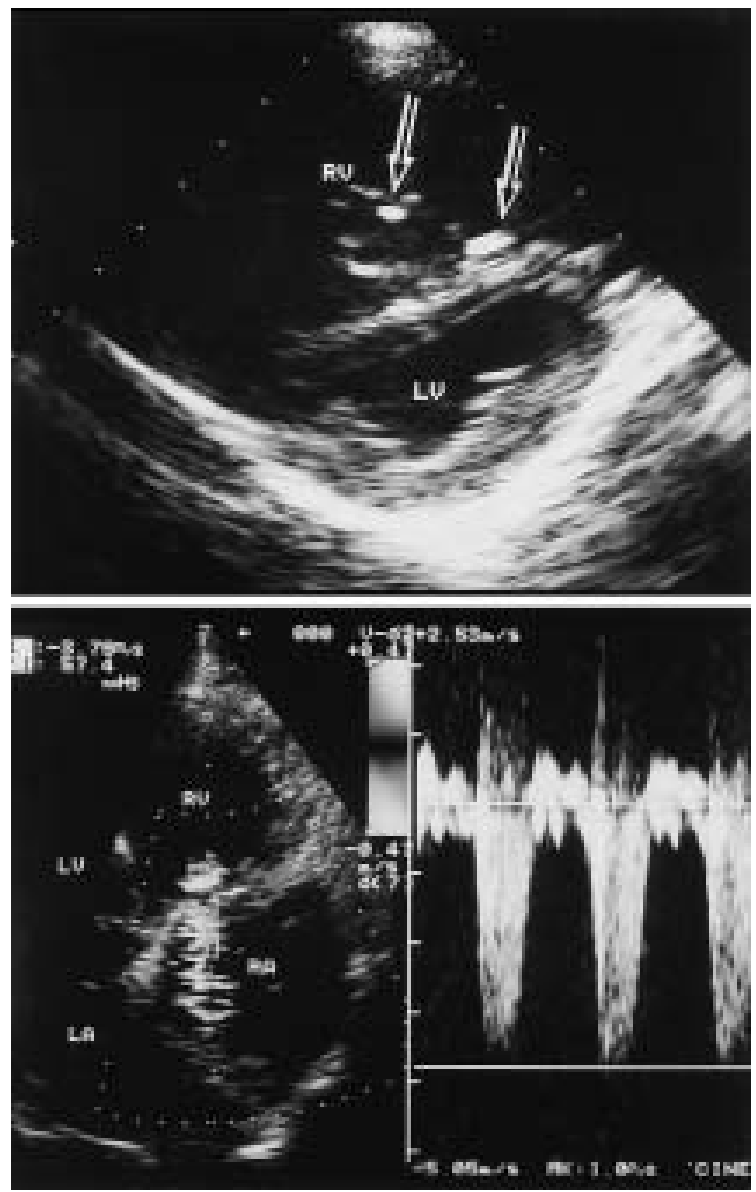

Fig. 2. Echocardiographs in Case No. 2, showing a severely dilated right ventricle, heartworms (arrows) at the tricuspid valve orifice and a flattened interventricular septum indicative of pressure and volume overloading of the right ventricle (top). Measurement of tricuspid valve regurgitation by continuous-wave Doppler guided by color flow Doppler calculated a pressure difference of $57.4 \mathrm{mmHg}$ between the right ventricle and atrium (bottom).

right-sided cardiomegaly and dilated and tortuous pulmonary arteries. Echocardiographic examination demonstrated a small number of heartworms in the right atrium and right ventricle and a flattening of the interventricular septum in the right parasternal short-axis views of the left ventricle, suggesting high right ventricular pressure and/or volume overload (Fig. 2). In addition, continuous-wave and color flow Doppler discovered a tricuspid regurgitant jet with a peak velocity of $3.79 \mathrm{~m} / \mathrm{sec}$ which indicated a pressure gradient of $57.4 \mathrm{mmHg}$ between the right ventricle and atrium (Fig. 2). Eight days after admission, ascitic fluid was increased. Despite treatments with fluid therapy and ascitic fluid removal, the dog's condition deteriorated and it died on the 18th day after admission. At autopsy, 2 adult male and 4 adult female worms in the right atrium and ventricle and 2 immature worms in the intra-pulmonary pulmonary artery (a total of 8 worms) were detected. Grossly, the lung revealed congestion, and black-mottled lesions were present in the right caudal lung lobe. Microscopically, pulmonary changes were similar to those in Case No. 1 and mainly composed of dead worm- and thrombus-related embolisms in the intra-pulmonary pulmonary arteries. Fragmented worms and thrombi adhering to them were detected in the left cranial and right caudal lung lobes. In addition, various sized thrombi were found in the large and small pulmonary arteries and capillaries and the thrombi were organizing by granulation tissue.

Case No. 3: A 23-month-old, male Siberian Husky was presented with a history of anorexia and depression. Physical examination revealed severe dehydration, pale mucous membranes, and a striking systolic murmur in the tricuspid valve region. Blood tests revealed leukocytosis $\left(286 \times 10^{2} /\right.$ $\mu l)$ and increased plasma alkaline phosphatase activity (273 $\mathrm{IU} / l)$ and glucose concentration $(215 \mathrm{mg} / \mathrm{d} l)$. The RBC count $\left(539 \times 10^{4} / \mu l\right)$, hematocrit $(36.7 \%)$ and hemoglobin concentration $(12.8 \mathrm{~g} / \mathrm{d} l)$ were within the reference ranges, but these values seemed to be influenced by dehydration. The result of a heartworm antigen test was positive. Echocardiography detected a mass of worms involving the tricuspid valve apparatus. From these clinical data, the dog was diagnosed with $\mathrm{CS}$, and heartworm extraction with a flexible alligator forceps by jugular venotomy was performed, but only two heartworms were removed. Postoperative medication including fluid therapy with Ringer's solution, blood transfusion, furosemide (Lasix ${ }^{\circledR}$, Aventis Pharma Ltd., Tokyo, Japan), aminophylline (Neophyllin ${ }^{\circledR}$, Eisai Co., Ltd., Tokyo, Japan), trapidil (Rocornal Tab ${ }^{\circledR}$, Mochida Pharmaceutical Co., Ltd., Tokyo, Japan) and ampicillin (Viccillin ${ }^{\circledR}$, Meiji Seika Kaisya Ltd., Tokyo, Japan), were given. The dog's condition improved gradually and it was discharged after 9 days of hospitalization.

Three dogs in this report were definitely diagnosed with CS on the basis of echocardiographic findings. Hemoglobinuria has been a characteristic sign in the conventional canine CS [1-3, 5, 6, 9, 12], but it was not macroscopically in our cases. Hemoglobinuria is due to intravascular hemolysis resulting from physical destruction of fragile erythrocytes by a worm mass at the tricuspid valve orifice $[3,6,9$, $12]$, but hemoglobinuria is not always seen in all dogs with CS $[2,6]$. It is suggested that the degree of hemolysis is influenced by heartworm conditions which produce an abnormal bloodstream at the tricuspid valve orifice and dysfunction of the valve [6]. In our 3 cases, a heartworm mass was observed echocardiographically at the tricuspid valve orifice and Case No. 2 had severe tricuspid regurgitation. Although the number of worms in Case No. 3 could not be determined, other dogs had relatively light worm burdens, which might have been not enough to produce visible hemoglobinuria.

The mechanism of CS development has been discussed for many years. As for the condition of the dogs, it is not always necessary for CS development to harbor heavy worms $[1,8,9,12]$. In fact, Atwell and Farmer recognized CS in a dog with just one heartworm infestation in the right 
atrium [2]. Kitagawa et al. suggested that retrograde migration of heartworms from the pulmonary arteries was induced by decreases in cardiac output and velocity, associated with pulmonary arterial embolism of dead worms and/or shocklike reaction caused by worm body extracts $[7,8]$. In addition, it is suggested that thromboemboli formed after worm death is the most important factor causing an increase in pulmonary arterial pressure [11], leading to a decline in cardiac output [7]. In our cases (No. 1 and No. 2), pathological examinations also demonstrated pulmonary arterial embolism associated with dead worms and thrombi, which would have contributed to the development of CS. It is interesting that the worms should have such a short life span, although their lives are approximately 5 years, ranging from 3 to 7 years $[4,9]$. None of these dogs had a history of adulticide therapy. The reason for this is unknown, but the host's immune response to heartworms might have been intense in the dogs reported here, as seen in feline heartworm disease [4].

As far as we know, the youngest age for spontaneous CS dogs is 18 months in the literature [2], on which unfortunately, data as to the number of worms recovered and the clinical course have not been available. Experimental CS has been induced as early as 7 months after inoculation with a large number of infective larvae [1]. The ages of the dogs in this report were confirmed by the pedigree proofs or owners. These 3 dogs had been exposed to the mosquito season twice and developed CS at the end of the second season. In spontaneous canine CS, it is uncommon for dogs with just two infective seasons to develop CS. The authors emphasize that a dog with heartworm infestation may have a potential risk of CS development if pulmonary arterial embolism were induced by dead worms or thrombi, regardless of the dog's age or number of worms.

\section{REFERENCES}

1. Atkins, C.E., Keene, B.W. and McGuirk, S.M. 1988. J. Vet. Intern. Med. 2: 36-40.

2. Atwell, R.B. and Farmer, T.S. 1982. J. Small Anim. Pract. 23: 675-685.

3. Calvert, C.A., Rawlings, C.A. and McCall, J.W. 1999. pp. 702-726. In: Textbook of Canine and Feline Cardiology, 2nd ed, (Fox, P.R., Sisson, D. and Moïse, N.S. eds.), W. B. Saunders Company, Philadelphia.

4. Dillon, R. 2000. pp. 937-963. In: Textbook of Veterinary Internal Medicine, 5th ed. (Ettinger, S.J. and Feldman, E.C. eds.), W.B. Saunders Company, Philadelphia.

5. Ishihara, K., Kitagawa, H., Ojima, M., Yagata, Y. and Suganuma, Y. 1978. Jpn. J. Vet. Sci. 40: 525-537.

6. Kitagawa, H., Sasaki, Y. and Ishihara, K. 1986. Jpn. J.Vet. Sci. 48: 99-103.

7. Kitagawa, H., Sasaki, Y., Ishihara, K. and Kawakami, M. 1990. Jpn. J. Vet. Sci. 52: 591-599.

8. Kitagawa, H., Sasaki, Y., Ishihara, K. and Kawakami, M. 1991. Am. J. Vet. Res. 52: 126-132.

9. Kittleson, M. D. 1998. pp. 370-401. In: Small Animal Cardiovascular Medicine (Kittleson, M.D. and Kienle, R.D. eds), Mosby, St. Louis.

10. Nomura, Y., Ibaraki, J. and Saito, Y. 1982. Bull. Azabu. Univ. Vet. Med. 3: 129-138 (in Japanese with English summary).

11. Sasaki, Y., Kitagawa, H. and Hirano, Y. 1992. J. Vet. Med. Sci. 54: 739-744.

12. Strickland, K.N. 1998. Clin. Tech. Small Anim. Pract. 13: 8895. 